\title{
CREPE: mathematical model for CRosstalking of Endothelial cells and hePatocytE metabolism
}

\author{
Giuseppe Valvano ${ }^{1}$, Gianni Orsi ${ }^{1}$, Maria Angela Guzzardi ${ }^{2}$, Federico Vozzi ${ }^{2}$, Giovanni Vozzi ${ }^{1}$
}

\begin{abstract}
The liver shows a close coexistence between endothelial cells and hepatocytes. Endothelial cells main purpose is to protect hepatocytes from blood vessel shear stress, acting as a barrier, but experimental evidences suggests that they could also play a role in regulating hepatocytes glucose metabolism. A well-known singular effect in hepatocyte-endothelial co-cultures is the reduction of glucose consumption respect to hepatocytes in single culture. Hepatocytes were shown to reduce their glucose consumption supporting energy needs of endothelial cells. Monti et al. have studied the effects of Endothelin-1 on Glucokinase activity in adult rat hepatocytes. They observed a reduction in hepatocytes Glucokinase catalytic rate, which is dependent of Endothelin-1 concentration. We developed CREPE (CRosstalking of Endothelial cells and hePatocytE metabolism), that is a mathematical model of the Endothelin-1 mediated crosstalk between hepatocytes (HepG2) and endothelial cells (Human Umbilical Vein Endothelial Cells) in a traditional static co-culture system. CREPE was validated against experimental data, showing good agreement with them. CREPE can be a starting point to develop predictive tools on complex and highly interconnected environments.
\end{abstract}

Index Terms - Computational Systems Biology, Cell crosstalk, Mathematical modeling, Endothelin-1, Glucokinase.

\section{INTRODUCTION}

$\mathrm{M}$ ANY attempts to model biological systems, such as biochemical pathways or intracellular environment, have been proposed during last years. There was the need to combine biological experiments to high-throughput experiments in order to maximize the results and minimizing the costs. Starting from online metabolic pathways databases such as KEGG [1], we previously developed HEMET $\beta$ (HEpatocyte METabolism mathematical model [2], [3]) and ENMET (ENdothelial cell METabolism mathematical model [4]), two virtual cell models that reproduced respectively hepatocyte and endothelial cell metabolism. HEMET $\beta$ [3] was developed with the idea to describe the cell metabolic architecture by considering its physical, chemical and cell-cell

Giuseppe Valvano, Gianni Orsi and Giovanni Vozzi are with Interdepartmental Research Center "E. Piaggio", Faculty of Engineering, University of Pisa, Via Diotisalvi 2, 56126 Pisa, Italy (E-mail: g.orsi@ centropiaggio.unipi.it; g.vozzi@ centropiaggio.unipi.it). Maria Angela Guzzardi and Federico Vozzi are with Institute of Clinical Physiology-CNR, via Moruzzi 1, 56124 Pisa, Italy. "Copyright (c) 2013 IEEE. Personal use of this material is permitted. However, permission to use this material for any other purposes must be obtained from the IEEE by sending an email to pubspermissions@ieee.org.” interactions, using as basic bricks the single enzymatic reactions of metabolic cell pathways. HEMET $\beta$ was implemented in Simulink® (The Mathworks Inc.) with modular layout, allowing the users to explore, understand or add/modify blocks easily. In this way we related the system theory language to the metabolic cell pathways, in order to associate the systemic view of the metabolic pathways with the quantitative results of simulation tool. The basic block was derived from the Michaelis-Menten kinetic for enzymatic reactions. It could be duplicated and connected to form complex reaction networks, which could represent the principal metabolic pathways such as glycolysis, Krebs cycle, etc. This reaction network was developed with the aim of simulating hepatocyte metabolism. ENMET was another cell model based on previous modular approach, which analyzed endothelial cell metabolism instead [4]. It integrated biochemical pathways and biochemical response to a physical stimulus: the software, in fact, processed secretion of endothelial products (Nitric Oxide and Endothelin-1) in response to shear stress action on endothelial cells [5]. However the models were able to describe only what happens in cells single cultures, that do not represents properly the liver environment, that at least see the cooperation of hepatocytes an endothelial cells. Hepatocyte co-cultures with nonparenchymal cells were shown to stabilize hepatocyte phenotype [6] and enhance its secretions. Co-cultures could also help us to understand how hepatocytes alter their metabolism in response to specific stimuli coming from their non-parenchymal neighbors, and what these cells need for their proliferation [7]. A better understanding of complex communication network underlying hepatocytes cross talking with non- parenchymal cells could for example suggest the best topological features to realize a scaffold for liver tissue engineering. Thus we developed CREPE (CRosstalking of Endothelial cells and hePatocytE metabolism), which merged the previous models in order to model metabolism of hepatocytes and endothelial cells co-culture. CREPE implemented the effect of Endothelin-1 on hepatocyte Glucokinase activity, the cell proliferation model of two cell types in co-culture and the tuning of albumin synthesis due to co-culture condition.

\section{HePatocyte Co-Cultures}

Many studies have been performed about the behavior of hepatocytes co-cultured with different kind of nonparenchymal cell: epithelial cells, stellate cells (Ito, fatstoring), sinusoidal endothelial cells, Kupffer cells, etc. [5-7] 
However our work is focused on hepatocytes co-culture with endothelial cells. Supported by endothelial cells hepatocytes not only enhance their primary metabolism, drug clearance and gene expression, but also maintain their shape and show an enhanced proliferation [5-8]. A singular effect in hepatocyteendothelial co-culture is the reduction of glucose consumption rate by hepatocytes, compared to hepatocytes in single culture. Hepatocytes are able extract energy for their cell functions from other metabolic pathways in addition to glucose metabolism, such as amino acids metabolism. Endothelial cells instead cannot get significant energy from this pathway. It suggests that a particular communication is established, so hepatocytes reduce their glucose consumption rate, supporting energy needs of endothelial cells. Monti et al. [8] have studied how Endothelin-1 acts on Glucokinase activity in adult rat hepatocytes. They observed a reduction in intracellular G6P (Glucose-6-Phosphate), glycogen content and a glucose release in the medium. Thinking Endothelin-1 effect on glucokinase activity could be important for a future development of a cross-talking model, we implement this effect to HEMET $\beta$ starting from Monti et al. experiment. To validate this model we started a series of cell cultures in vitro using methods described in the following paragraph and in other studies about cross-talking [5].

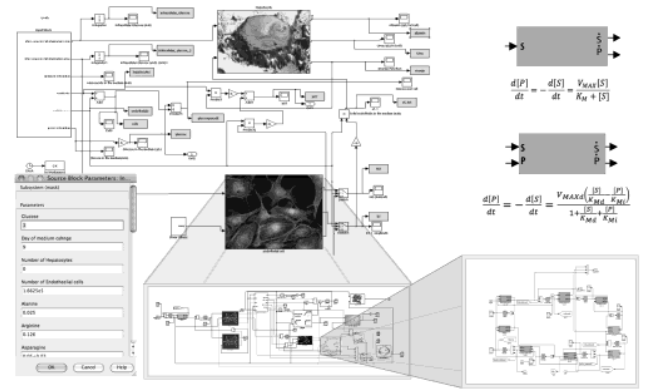

Fig. 1: CREPE user-friendly interface and modeling approach. It is possible to see in the main interface two principal blocks, the upper one that simulates the hepatocyte metabolism and the other one that simulates the endothelial cell metabolism. Each block is composed by a set of sub-blocks that represent the principal metabolic pathways of the cell, and each pathway is a net composed by the two base blocks (green and orange blocks). The base blocks implement the Michaelis-Menten equations for irreversible and reversible enzymatic reactions.

\section{MATERIALS AND METHODS}

\section{A. Cell Cultures}

The human cell line HepG2 was used as an alternative to primary human hepatocytes. The cell culture medium was MEM (glucose $1 \mathrm{~g} / \mathrm{L}$ ) supplemented with 5\% FBS, $100 \mathrm{U} / \mathrm{mL}$ penicillin, $100 \mu \mathrm{g} / \mathrm{mL}$ streptomycin, $1 \%$ glutamine, $2 \%$ MEM nonessential amino acids, and $2 \%$ vitamins. HepG2 were cultured in $75 \mathrm{~cm}^{2}$ flasks with complete MEM. For their use in experiments, they were detached with $0.05 \%$ trypsin with $0.02 \%$ EDTA, and seeded on glass slides of $12 \mathrm{~mm}$ diameter placed in 24-multiwell plate. HepG2 were seeded at a density of $5 \times 10^{4}$ cells per well for monoculture tests, and at a density of $8 \times 10^{4}$ cells per well for co-culture experiments. HUVEC were extracted using a trypsin-based treatment. The umbilical vein was cannulated and washed with PBS. Then, it was closed at one end, filled with $0.05 \%$ trypsin with $0.02 \%$ EDTA in $\mathrm{PBS}$, and left at $37^{\circ} \mathrm{C}$ for $15 \mathrm{~min}$. The solution was recovered and centrifuged $(900 \mathrm{rpm}, 5 \mathrm{~min})$, and the cell-containing pellet was suspended in a fresh medium. The cells were counted using a Burker chamber, assessed for vitality through a trypan blue exclusion assay (routinely greater than 90\%), and seeded for amplification in a $25 \mathrm{~cm}^{2}$ flask coated with $0.5 \%$ gelatin. To maintain and grow the cells, M199 was supplemented with $10 \% \mathrm{FBS}, 100 \mathrm{U} / \mathrm{mL}$ penicillin, $100 \mu \mathrm{g} / \mathrm{mL}$ streptomycin, $1 \%$ glutamine, and $1 \%$ bovine brain extract; this is referred to as complete M199. When at confluence, HUVEC were detached with trypsin and seeded on glass slides pretreated with $0.5 \%$ gelatin at a density of $5 \times 10^{4}$ per well for static monoculture tests, at a density of $8 \times 10^{3}$ per well for coculture experiments. For the co-culture experiments, HUVEC and HepG2 were suspended together and seeded onto the slides. The HUVEC: HepG2 seeding ratio was. 1:10, which mimics the ratio between endothelial cells and hepatocytes in human liver, where the two types of cells have homotypic and heterotypic connections. Experiments were performed for 5 days $(120 \mathrm{~h})$.

\section{B. MTT assay}

Cell viability was assessed by the MTT assay. It uses a yellow compound that is oxidized by mitochondrial enzymes to a purple compound soluble in dimethyl sulfoxide. The cell suspension was centrifuged at $900 \mathrm{rpm}$ for $5 \mathrm{~min}$, and the pellet was suspended in $200 \mu \mathrm{L}$ of fresh medium and placed in 96-multiwell plate. Twenty microliters of MTT solution $5 \mathrm{mg} / \mathrm{mL}$ was added to the cell suspension. After $12 \mathrm{~h}$ medium was removed, the pellet suspended in $200 \mu \mathrm{L}$ dimethyl sulfoxide, and the absorbance measured at $540 \mathrm{~nm}$.

TABLE I

ENZYMES KINETIC RATES

\begin{tabular}{cc}
\hline \hline Enzyme & Kinetic rate \\
\hline Glucokinase & $G K=\frac{V \max _{G K}[A T P][G l u]}{K_{m_{G K}+[A T P][G l u]}}$ \\
$\begin{array}{c}\text { Glucose-6-phosphate } \\
\text { isomerase }\end{array}$ & $G P I=\frac{V_{\max G P I}\left(\frac{[G 6 P]}{K_{m G I_{D}}}-\frac{[F 6 P]}{K_{m G I_{I}}}\right)}{1+\frac{[G 6 P]}{K_{m G P I_{D}}+\frac{[F 6 P]}{K_{m G P I_{I}}}}}$ \\
Phosphoglucomutase & $P G M=\frac{V_{\max P G M}\left(\frac{[G 6 P]}{K_{m P G M_{D}}}-\frac{[G 1 P]}{K_{m P G M_{I}}}\right)}{1+\frac{[G 6 P]}{K_{m P G M_{D}}+\frac{[G 1 P]}{K_{m P G M_{I}}}}}$ \\
G6P Dehydrogenase & $G 6 P D=\frac{V_{\max G G P D}[G 6 P]}{K_{m G G P D}\left(\frac{[N A D P H]}{K_{i G 6 P D}}+1\right)+[G 6 P]}$ \\
\hline \hline
\end{tabular}

Glu $\rightarrow$ Glucose; G6P $\rightarrow$ Glucose 6 phosphate; F6P $\rightarrow$ Fructose 6 phosphate; G1P $\rightarrow$ Glucose 1 phosphate; Vmax and affinity constants numerical values are detailed in [4].

\section{Glucose and Albumin assay}

Metabolite concentrations were determined in the medium using commercial kits in accordance with manufacturer instructions and then converted to absolute quantities by multiplying by the total volume. In particular, the glucose concentration was assessed using the Glucose Test Kit (Megazyme International Ireland, Bray, Ireland), a 
colorimetric assay based on glucose-oxidase and peroxidase reactions. Human albumin concentration was evaluated by an ELISA immunochemical assay (Bethyl Laboratories, Montgomery, TX).

TABLE II

ESTEEMED AND MEASURED PARAMETERS

\begin{tabular}{|c|c|c|}
\hline Parameter & Meaning & Value \\
\hline$a_{H}$ & Hepatocyte area & $4.50 \cdot 10^{-10} \mathrm{~m}^{2}$ \\
\hline$a_{E}$ & Endothelial cell area & $4.03 \cdot 10^{-10} \mathrm{~m}^{2}$ \\
\hline$A_{W}$ & Well area (measured) & $3 \cdot 10^{-4} \mathrm{~m}^{2}$ \\
\hline$C_{H}$ & $\begin{array}{l}\text { Hepatocytes basal rate } \\
\text { of proliferation }\end{array}$ & $0.0380 \pm 0.00412 \mathrm{~h}^{-1}$ \\
\hline$C_{E}$ & $\begin{array}{l}\text { Endothelial cells basal } \\
\text { rate of proliferation }\end{array}$ & $0.0408 \pm 0.00347 \mathrm{~h}^{-1}$ \\
\hline$S_{C}$ & $\begin{array}{l}\text { Substrate function } \\
\text { critical value }\end{array}$ & $(6.68 \pm 1,31) \cdot 10^{-5} \mathrm{mM}$ \\
\hline$K_{I E t l}$ & $\begin{array}{l}\text { Non-competitive } \\
\text { inhibition constant }\end{array}$ & $2.231 \cdot 10^{-3} \mathrm{mM}$ \\
\hline$K$ & $\begin{array}{l}\text { Max GK genetic } \\
\text { inhibition factor }\end{array}$ & $0.6208 \pm 0,182$ \\
\hline$m$ & $\begin{array}{c}\text { GK genetic inhibition } \\
\text { Hill coefficient }\end{array}$ & $2.318 \pm 0,463$ \\
\hline$\theta$ & $\begin{array}{c}\text { GK genetic half } \\
\text { inhibition concentration }\end{array}$ & $(1.057 \pm 0,18) \cdot 10^{-9} \mathrm{mM}$ \\
\hline$C_{G H}$ & $\begin{array}{l}\text { Hepatocyte glucose } \\
\text { consumption rate }\end{array}$ & $(0.478 \pm 0.0227) \cdot 10^{-7} \mathrm{~h}^{-1}$ \\
\hline$C_{G E}$ & $\begin{array}{c}\text { Endothelial cell glucose } \\
\text { consumption rate }\end{array}$ & $(0.256 \pm 0.0136) \cdot 10^{-7} \mathrm{~h}^{-1}$ \\
\hline$R_{G H}$ & $\begin{array}{c}\text { Hepatocyte glucose } \\
\text { release rate }\end{array}$ & $(0.258 \pm 0,0229) \cdot 10^{-8} \mathrm{~h}^{-1}$ \\
\hline$\alpha_{a l b}$ & $\begin{array}{c}\text { Albumin maintenance } \\
\text { term }\end{array}$ & $0.0187 \pm 0.00251 \mathrm{~h}^{-1}$ \\
\hline$\beta_{0}$ & $\begin{array}{c}\text { Basal Albumin secretion } \\
\text { rate }\end{array}$ & $5.03 \pm 1.87 \mathrm{mM}^{-1} \mathrm{~h}^{-1}$ \\
\hline$K_{a l b}$ & $\begin{array}{c}\text { Albumin max } \\
\text { enhancement factor }\end{array}$ & $130 \pm 0.987$ \\
\hline$\theta_{a l b}$ & $\begin{array}{c}\text { Albumin half } \\
\text { enhancement ratio }\end{array}$ & $0.0955 \pm 0.00147$ \\
\hline$v$ & Albumin Hill coefficient & $2.47 \pm 0.263$ \\
\hline
\end{tabular}

All parameters (except well area that was measured) result from parameter estimation using nonlinear least squares method on experimental data. Values are expressed as mean \pm standard deviation.

\section{MODEL DEVELOPMENT}

\section{A. Hemet $\beta$ and ENMET models}

The objective of HEMET $\beta$ model was to implement the main pathways of hepatocyte metabolic network, following online database such as KEGG [1] and consolidated biochemistry [9]. We used differential equations, system theory approach [10], [11] and energetic consideration, such as availability of ATP and other high-energy molecules used in biosynthesis processes [12]. As explained above the basic blocks derives from Michaelis-Menten [13] kinetic:

$\frac{d[P]}{d t}=-\frac{d[S]}{d t}=\frac{V_{\max }[S]}{K_{m}+[S]}$

where $\mathrm{P}(\mathrm{mM})$ is the product of an enzymatic reaction, $\mathrm{S}(\mathrm{mM})$ is the substrate, and $\mathrm{K}_{M}$ and $\mathrm{V}_{\max }$ are the Michaelis-Menten affinity constant and the maximum velocity of enzyme respectively. The other basic block of HEMET $\beta$ derives from the Michaelis Menten equation for equilibrium reactions:

$\frac{d[P]}{d t}=-\frac{d[S]}{d t}=\frac{V_{\max }\left(\frac{[S]}{K_{m d}}-\frac{[P]}{K_{m i}}\right)}{1+\frac{[S]}{K_{m d}}+\frac{[P]}{K_{m i}}}$ where $\mathrm{K}_{\mathrm{Md}}(\mathrm{mM})$ and $\mathrm{K}_{\mathrm{Mi}}(\mathrm{mM})$ are respectively direct and inverse reaction affinity constants. In metabolic pathways many reactions are multi-substrate reaction, so we need more general reaction blocks. We supposed that the reactive event considers all reactants in the same instant, so a general equation in which we have $\mathrm{m}$ products and $\mathrm{n}$ substrates can be written as:

$$
\begin{aligned}
& \frac{d\left[P_{m}\right]}{d t}=-\frac{d\left[S_{n}\right]}{d t}=\frac{V_{\max } \prod_{n}\left[S_{n}\right]}{K_{m}+\prod_{n}\left[S_{n}\right]} \\
& \frac{d\left[P_{m}\right]}{d t}=-\frac{d\left[S_{n}\right]}{d t}=\frac{V_{\max }\left(\frac{\prod_{n}\left[S_{n}\right]}{K_{m d}}-\frac{\prod_{m}\left[P_{m}\right]}{K_{m i}}\right)}{1+\frac{\prod_{n}\left[S_{n}\right]}{K_{m d}}+\frac{\prod_{m}\left[P_{m}\right]}{K_{m i}}}
\end{aligned}
$$

where affinity constants are obtained as the mean of these for all compounds. Following system theory approach is possible to convert entire metabolic pathways as series of ODE (Ordinary Differential Equations) using metabolites concentration as state variables and equations (3-4) as state equations. Considering these equations as elementary Simulink ${ }^{\circledR}$ blocks and following block scheme algebra rules, linking these blocks in series and/or parallel can create an entire pathway (Fig. 1). Each pathway constitutes a block that can be linked with other blocks if they have common metabolites. The block structure is user-friendly and highly expandable, in fact it is possible to easily define new cell types by adding or removing some blocks as we did in a previous work in which we created ENMET (ENdothelial cell METabolism mathematical model [4]).

\section{B. Modeling Endothelin-1 effect}

Glucokinase is the enzyme responsible of the glucose to Glucose 6 phosphate (G6P) conversion after its transport into intracellular medium. G6P cellular content results equal to algebraic sum of G6P produced and G6P consumed by metabolic pathways such as glycolysis, pentose phosphate pathway, and glycogen synthesis; in particular the production / consumption rate that defined G6P state variable is:

$$
\frac{d[G 6 P]}{d t}=G K-G P I-P G M-G 6 P D
$$

The significance of each term is explained in Table I [3]. Glucokinase (GK) is the enzyme responsible of immediate glucose conversion in Glucose 6 phosphate after its transport into intracellular medium. Because it is the first enzyme in glucose metabolic pathway, it can influence with its kinetic the velocity of the entire chain. If something causes a slowing down of GK activity, the entire cell glucose metabolism is slowed down. Monti et al. [8] found that endothelin-1 (Et-1) can reduce GK maximum velocity in hepatocytes. Endothelin1 is a protein, with a vasoconstrictor effect, secreted by endothelial cells, so it seems reasonable to consider this effect in our model of hepatocytes and endothelial cells in co-culture. We tried to use two different models to reply Et-1 effect on GK: in the first one we supposed that Et-1 acted as a noncompetitive inhibitor [13] of GK, by the following equation:

$$
V_{\max G K}=V_{\max 0} 1+\frac{[E t 1]}{K_{I E T 1}}
$$


where $\mathrm{V}_{\max 0}(\mathrm{mM} / \mathrm{s})$ is basal maximum velocity of Glucokinase, [Et-1] (mM) is Et-1 concentration in the medium and $\mathrm{K}_{\mathrm{IEt} 1}$ is the inhibition constant of the enzyme (esteemed, see Table II). This vision of Et-1 effect seems to be forced; in fact a better physiological hypothesis is that Endothelin-1 causes a signal transduction cascade in hepatocytes in order to act as a genetic inhibitor. So equation (6) was replaced with following one, which is more suited to describe genetic inhibition [14]:

$V_{\max G K}=V_{\max 0}\left(1-\frac{K[E t 1]^{m}}{[E t 1]^{m}+\theta^{m}}\right)(7)$

where $\theta(\mathrm{mM}), \mathrm{K}$ and $\mathrm{m}$ (adimensional) are parameters esteemed with a curve fitting tool. Akaike Information Criterion (AIC) and Bayesian Information Criterion (BIC) [21] give us a tool for choose the best model between (6) and (7). Given a likelihood function $L$ to maximize in the fitting, two criteria consider the number of parameters $k$ and the experimental data $n$.

$$
A I C=2 k-2 \ln (L) \quad(8) \quad B I C=k \ln (n)-2 \ln (L)
$$

In general terms given a set of candidate models for a data set, the preferred model is the one with the minimum AIC or BIC value. Thus these criterions not only reward goodness of fit, but also include a penalty that is an increasing function of the number of estimated parameters. This penalty discourages overfitting, so we used these criterions to justify the presence of a greater number of parameters in the new model. A difference between $\mathrm{AIC}$ and $\mathrm{BIC}$ is that BIC penalizes more free parameters than AIC, so we decided to compare (6) and (7) with both indices, with a likelihood function based on sum of squared residuals (SSR) that drove to the following formulas:

$$
\begin{aligned}
A I C & =2 k+n \ln \left(\frac{S S R}{n}\right) \quad(10) \quad B I C=k \ln (n)+n \ln \left(\frac{S S R}{n}\right) \\
S S R & =\sum_{i=1}^{n}\left(y_{i}-x_{i}\right)^{2} \quad(12)
\end{aligned}
$$

where $y_{i}$ is the fitting curve and $x_{i}$ is the experimental data point. On the basis of these indices (Table III) genetic inhibition model (7) gave better results in comparison with non-competitive inhibition model (6), because the AIC/BIC scores are less in the former model than in the latter one. Due to this result even if the number of parameters is increased the overfitting issue is neglected in this case.

TABLE III

COMPARISON BETWEEN TESTED MODELS

\begin{tabular}{ccc}
\hline \hline & $\begin{array}{c}\text { Non } \\
\text { competitive } \\
\text { inhibition }\end{array}$ & Genetic inhibition \\
\hline$n$ & 4 & 4 \\
$k$ & 1 & 3 \\
$S S R$ & 0.003317 & 0.0005808 \\
$A I C$ & -26.3800 & -29.3496 \\
$B I C$ & -26.9937 & -31.1907 \\
\hline \hline
\end{tabular}

$\mathrm{AIC}=\mathrm{n} \cdot \ln (\mathrm{SSR} / \mathrm{n})+2 \mathrm{k}, \mathrm{BIC}=\mathrm{n} \cdot \ln (\mathrm{SSR} / \mathrm{n})+\mathrm{k} \cdot \ln (\mathrm{n})$ where $\mathrm{n}$ is the number of experimental points, $\mathrm{k}$ is the number of esteemed parameters and SSR is the sum of square residuals.

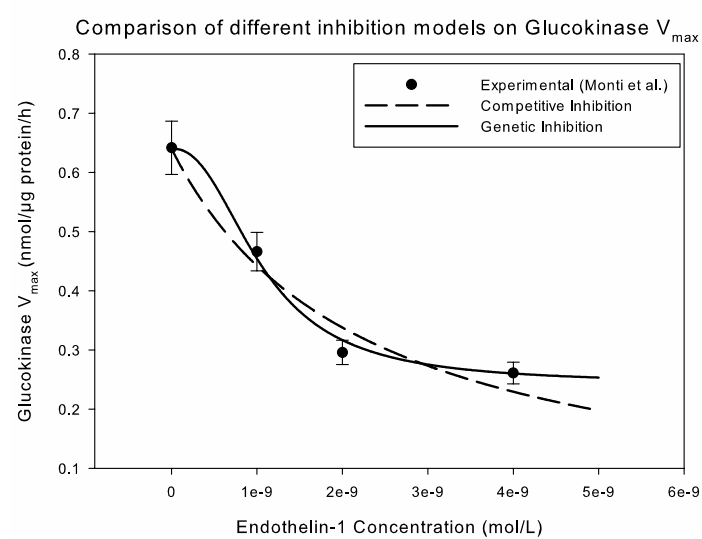

Fig. 2: Effect of Et-1 on Glucokinase Vmax. Circles indicate experimental values obtained from (Monti et al. 2000), error bars represent the standard deviations of measured data. Solid and dashed lines represent respectively equation (6) and equation (7).

\section{Cell proliferation model}

In HEMET, HEMET $\beta$ and ENMET cell proliferation was modeled with a logistic function:

$$
\frac{d N(t)}{d t}=C N(t)-b[N(t)]^{2}
$$

where $\mathrm{C}$ and $\mathrm{b}$ are respectively cell grow rate and death rate. The logistic function is suitable for cell proliferation model as it is for all kind of population growth model. It reflects the initial phase of cell growing, given by the exponential increment (linear term). In the middle and in the late phase the logistic function is appropriate for mimicking the competition between cells (quadratic term) that arise from the lack of resources, and that settles the system in steady-state. In this model we consider a less compact equation derived from equation (13), by which we correlated the death term to contact inhibition and substrate lack. Hepatocytes as endothelial cells are affected by contact inhibition, but in our culture only endothelial cells are affected from substrate lack. Hepatocytes do not suffer from substrate lack, because they can get energy from other substrates, as we told before. We formulated the following equations:

$$
\begin{aligned}
& \frac{d N_{H}(t)}{d t}=C_{H} N_{H}(t)\left[1-\frac{a_{H} N_{H}(t)+a_{E} N_{E}(t)}{A_{w}}\right] \\
& \frac{d N_{E}(t)}{d t}=C_{E} N_{E}(t)\left[1-\frac{a_{H} N_{H}(t)+a_{E} N_{E}(t)}{A_{w}}-\frac{S c}{S} N_{E}(t)\right]
\end{aligned}
$$

each term is summarized in Table II. The terms $a_{H}$ and $a_{E}$ represent hepatocyte and endothelial cell area respectively, while $A_{W}$ is the whole area available for cell adhesion $(\sim 3$ $\left.\mathrm{cm}^{2}\right)$. These area were calculated considering hepatocyte as a $24 \mu \mathrm{m}$ diameter circular cell, and endothelial cell as $12.5 \times 32$ $\mu \mathrm{m}^{2}$ rectangle. Last term in equation (15) indicates the death term due to lack of substrates. $\mathrm{S}$ is calculated as the sum of substrates [3]:

$$
S=[G l u(t)]+\sum_{i}[A A(t)]_{i}
$$

where $[\mathrm{Glu}(\mathrm{t})](\mathrm{mM})$ is the glucose concentration in the medium and $[\mathrm{AA}(\mathrm{t})]_{\mathrm{i}}(\mathrm{mM})$ is the $\mathrm{i}$-th aminoacid concentration in the medium. In the software the user can set the initial number of each cell type with a dialog box; the integration of equation (14) and (15) start from $18^{\text {th }}$ hour, because cells do not proliferate soon after seeding. The meaning of this 
equation set is that cell culture follows a logistic curve that is inhibited by a contact inhibition (geometric terms) and a substrate lack inhibition (substrate function term, present only in the equation of endothelial cell growth).

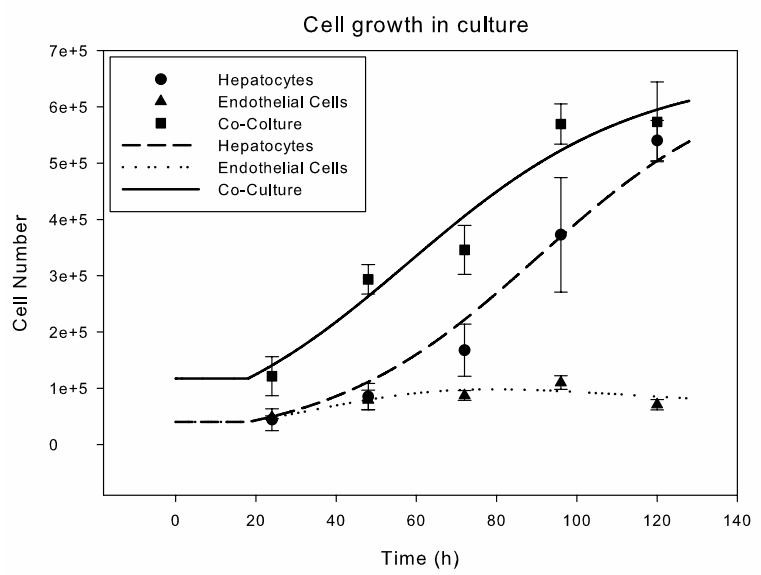

Fig. 3: Measured and simulated cell count in function of time. Solid line, dashed and dotted line represent respectively the cell number simulated by CREPE in the case of co-culture, single culture of hepatocytes and single culture of endothelial cells respectively, while squares, circles and triangles represent their experimental data shown with their standard deviation.

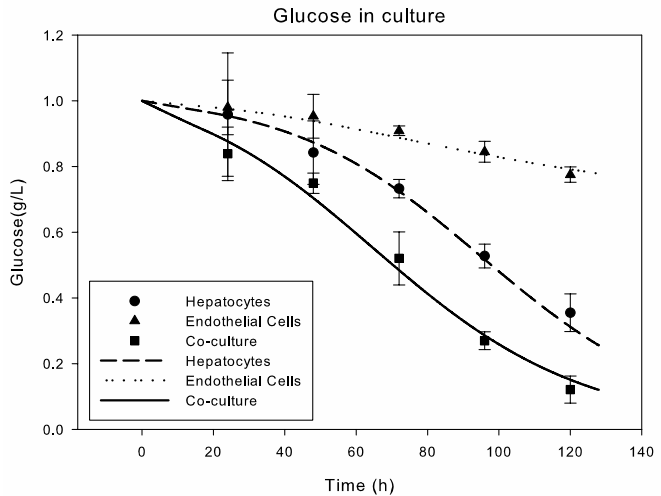

Fig. 4: Measured and simulated glucose trend in culture medium. Solid line, dashed and dotted line represent the glucose trends simulated by CREPE in the case of co-culture, single culture of hepatocytes and single culture of endothelial cells respectively, while squares, circles and triangles represent their experimental data shown with their standard deviation.

\section{Glucose uptake}

The slowing down of GK activity could cause an accumulation of glucose in intracellular environment, if it is not balanced with glucose uptake, so we decided to insert a release term in the glucose uptake equation:

$$
\frac{d[G l u]}{d t}=-C_{G H} N_{H}[G l u]-C_{G E} N_{E}[G l u]+R_{G H} N_{H}\left[G l u_{I H}\right]
$$

where $\mathrm{C}_{\mathrm{H}}, \mathrm{C}_{\mathrm{E}}$ and $\mathrm{R}_{\mathrm{H}}$ are esteemed parameters (subscripts $\mathrm{H}$ and $\mathrm{E}$ are relative to hepatocytes and endothelial cells respectively), $\mathrm{N}_{\mathrm{H}}$ and $\mathrm{N}_{\mathrm{E}}$ are the number of cells in the well and $[\mathrm{Glu}]$ and $\left[\mathrm{Glu}_{\mathrm{IH}}\right]$ are the glucose concentration in the medium and in the hepatocyte intracellular environment.

\section{E. Albumin biosynthesis}

Albumin is one of principal markers of hepatocyte metabolic activity. Albumin is a plasma protein that acts as a carrier of fatty acid because their hydrophobic properties do not allow their transport in plasma without its action. It is reasonable to assume that hepatocytes secrete albumin in response to fatty acids presence. In fact in HEMET $\beta$ [3] albumin biosynthesis follows the dynamic described by equation:

$$
\frac{d[A l b]}{d t}=\beta_{a l b}[P a l][A T P]-\alpha_{a l b}[A l b]
$$

where $[A l b]$ is albumin concentration $(\mathrm{mM}),[\mathrm{Pal}]$ is palmitate concentration $(\mathrm{mM})$ and $[A T P]$ is ATP concentration $(\mathrm{mM})$. $\beta_{a l b}$ and $\alpha_{a l b}$ are kinetic constants derived in [3]. Albumin rate of production is proportional to palmitate concentration (if ATP is available), in order to represent the ability of hepatocyte to secrete albumin in response to the presence of fatty acids. Note that the term $-\alpha_{a l b}[A l b]$ does not denote a term of consumption but allows varying the albumin production rate only when the palmitate concentration varies. The evidence that in co-culture the enhancement of hepatospecific genes is related to the heterotypic contact between the two cell types [6], led us to investigate on the possibility of modelling the heterotypic contact. Furthermore Brieva et al. [22] found that in hepatocytes co-culture with fibroblasts, the enhancement of albumin synthesis is reduced if fibroblasts do not express ecadherin on their membrane. So we supposed that this phenomenon is general for the contact with all type of nonparenchymal cell, in particular for endothelial cells. We consider that the activation of hepatospecific genes follows a typical genetic activation curve [14] with the membrane proteins concentration. Endothelial cells membrane proteins in contact with the single hepatocyte are assumed to be proportional to the number of endothelial cells in contact with one hepatocyte. Assuming that the cells in co-culture are uniformly distributed, the number of endothelial cells in contact with the single hepatocyte is equal to the ratio $r$ of endothelial cells number and hepatocytes number in the coculture. So we replaced in (17) the constant $\beta_{a l b}$ with the following equation:

$$
\beta_{a l b}=\beta_{0}+\frac{K_{a l b} r^{v}}{r^{v}+\theta_{a l b}^{v}} \quad(18) \quad r=\frac{N_{E}(t)}{N_{H}(t)}
$$

where $N_{E}$ and $N_{H}$ are the endothelial cells number and hepatocytes number in the well, described by (14) and (15). The parameters $\beta_{0}, K_{a l b}\left(\mathrm{mM}^{-1} \mathrm{~s}^{-1}\right), v$ and $\theta_{a l b}$ are esteemed (Table II). The differential equations of the model were implemented in the Simulink $®$ environment and solved using the Rosenbrock algorithm with an integration step fixed at 0.01. Unknown parameters were estimated using the Simulink Parameter Estimation Toolbox, by a non-linear least squares method using Levenberg-Marquardt algorithm, whose cost function was the sum of square error (SSR). As lower/upper bounds, the maximum velocity of known enzymatic reaction, and stoichiometric ratios were used [15-17]. The optimization problem was high dimensional, and is recognized that the parameter sensitivity is in general "sloppy" [18,19] when modeling biological systems. In our case for assessing the reliability of estimated parameters we ran several parameter estimation with randomized parameter initial condition, in order to check the convergence of parameter values. Clever optimization schemes [20] could be implemented in the future for improved parameter estimation reliability. 


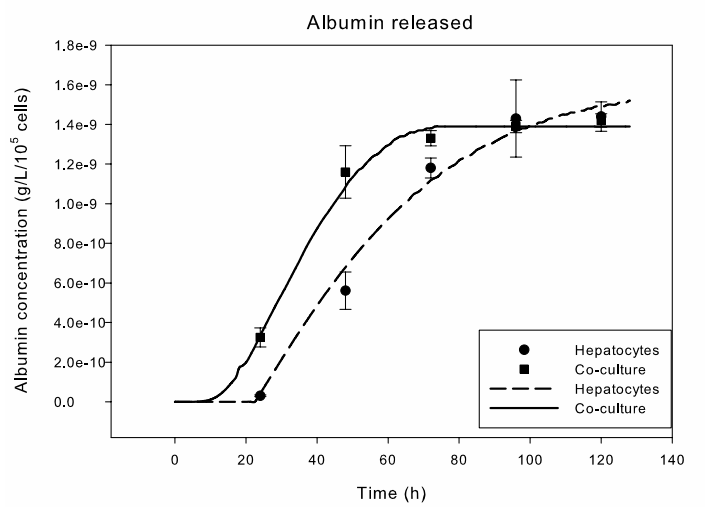

Fig. 5: Measured and simulated albumin concentration in culture medium. Continue and dashed represent the albumin trends simulated by CREPE in the case of co-culture and single culture of hepatocytes respectively, while squares and circles represent their experimental data shown with their standard deviation.

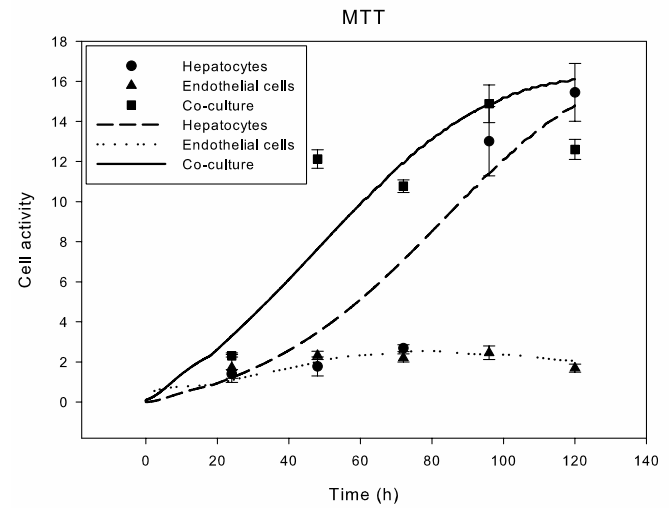

Fig. 6: Measured and simulated MTT test in function of time. Solid, dashed and dotted line represent cell energy function simulated by CREPE in the case of co-culture, single culture of hepatocytes and single culture of endothelial cells respectively. Squares, circles and triangles represent relative experimental data with their standard deviation. Solid curves, obtained by multiplying single cell energy function for the number of cells in culture medium, shows the same trend of experimental data derived from MTT tests.

\section{RESULTS AND DISCUSSION}

\section{A. Endothelin-1 effect}

We simulated Monti et al. [8] experiment starting the simulation with $10^{6}$ cells seeded, in a typical medium containing $12 \mathrm{mMol} /$ lit glucose and $1.2 \mathrm{pMol} /$ lit insulin. The first test was conducted without Endothelin-1, while the second with $2 \mathrm{nMol} /$ lit Endothelin-1. We calculated the total G6P in the culture $(\mathrm{G} 6 \mathrm{P} /$ cell $\times$ cell number) obtaining $\Delta \mathrm{G} 6 \mathrm{P}$ $=-12.32 \mu \mathrm{Mol} / \mathrm{lit}$, a value similar to Monti et al. study. This result is important not only for the validation of our hypothesis regarding this effect, but also for a further validation of the previous model HEMET $\beta$ approach. It is possible to appreciate the high expandability of our approach: we changed a block and the system reacts well for the simulation two experiment (our and Monti's one).

\section{B. Cell proliferation model and MTT test}

Deterministic simulations of ODEs system were performed with $1 \mathrm{~g} / \mathrm{lit}$ glucose in cell culture medium, amino acid content as the medium culture one. The initial number of cells considered was described above, and is summarized in Table IV. We used part of the experimental dataset to estimate the parameters of the equation set described in this paper, and part of the dataset to validate our model (each the co-culture model each the single culture model with the new features). As shown in figures 3-6 we validated the model for the simulation of hepatocytes cultures, endothelial cell cultures and their coculture. We can see in Figure 3 that both equation (14) and (15) represent well experimental cell proliferation either in case of simple culture than the co culture case. Endothelial cells (dotted line) in accord with experimental data suffer the lack of nutrients in the medium starting from the fourth day. Co-culture trend (solid line) is in part different from the experimental trend in the third and fourth day, maybe because a particular communication regulates the proliferation in the co-culture in order to maintain a certain ratio between the two cell populations, so hepatocytes seems to wait the endothelial cells in the third day and then they continue to proliferate until endothelial cells are no longer able to proliferate due to the lack of nutrients (fifth day). However these hypotheses need more investigation, as the role of cross-talking in the proliferation of the two cell population. MTT test experimental data are associated with cell energy state (Figure 6), obtained by multiplying the cell "energy function" for cell number [2], [3], [23]. So CREPE reflected well the interaction between these two different cell types. It is an important improvement from previous single cell models (HEMET, HEMET $\beta$, ENMET), which did not take in account in any manner the complexity of a real tissue. CREPE, instead, take in account a more physiological and realistic situation for cells. It will lead to have a quantitative prediction model that replies the real environment where hepatocytes and endothelial cells live.

\section{Glucose uptake}

Glucose trend in the medium follows exactly the experimental data (Fig. 4) except in the case of co-culture. It should be noted that it is a reflection of the error in the last three days of the proliferation model. In fact it is evident that a greater glucose consumption results from a greater number of cells, and this one results from an error in the proliferation model. Great deviations of experimental data in the first day are probably due to a different starting condition of the cultures. Thus glucose uptake model results mimicking well experimental behaviour. Endothelin-1 is able to slow down hepatocytes glucose metabolism, but it is not sufficient to slow down significantly the global glucose uptake, as we can see in Fig. 4. Maybe this is due to the state of hepatocytes during the experiment or to other factors that we have not considered yet.

TABLE IV

SimULATION INITIAL STATE DATA

\begin{tabular}{cccc}
\hline \hline Parameter & $\begin{array}{c}\text { Hepatocyte } \\
\text { culture }\end{array}$ & $\begin{array}{c}\text { Endothelial } \\
\text { culture }\end{array}$ & Co-culture \\
\hline $\begin{array}{c}\text { Hepatocytes } \\
\text { seeded }\end{array}$ & $5 \cdot 10^{4}$ cells & 0 & $8 \cdot 10^{4}$ cells \\
$\begin{array}{c}\text { Endothelial } \\
\text { cells seeded }\end{array}$ & 0 & $5 \cdot 10^{4}$ cells & $8 \cdot 10^{3}$ cells \\
\hline \hline
\end{tabular}


This article has been accepted for publication in a future issue of this journal, but has not been fully edited. Content may change prior to final publication. TBME-01493-2012.R2

TABLE V

SIMULATION INITIAL STATE DATA

\begin{tabular}{cccc}
\hline \hline Parameter & Value & Parameter & Value \\
\hline Glucose & $1 \mathrm{~g} / \mathrm{lit}$ & Istidine & $0.0420 \mathrm{~g} / \mathrm{lit}$ \\
& & Leucine & $0.0520 \mathrm{~g} / \mathrm{lit}$ \\
Alanine & $0.0250 \mathrm{~g} / \mathrm{lit}$ & Lysine & $0.0725 \mathrm{~g} / \mathrm{lit}$ \\
Arginine & $0.1260 \mathrm{~g} / \mathrm{lit}$ & Methionine & $0.0150 \mathrm{~g} / \mathrm{lit}$ \\
Asparagine & $0.0800 \mathrm{~g} / \mathrm{lit}$ & Proline & $0.0400 \mathrm{~g} / \mathrm{lit}$ \\
Aspartate & $0.1313 \mathrm{~g} / \mathrm{lit}$ & Serine & $0.0250 \mathrm{~g} / \mathrm{lit}$ \\
Cysteine & $0.0750 \mathrm{~g} / \mathrm{lit}$ & Tyrosine & $0.0519 \mathrm{~g} / \mathrm{lit}$ \\
Phenylalanine & $0.0320 \mathrm{~g} / \mathrm{lit}$ & Tryptophan & $0.0100 \mathrm{~g} / \mathrm{lit}$ \\
Glycine & $0.0500 \mathrm{~g} / \mathrm{lit}$ & Valine & $0.0460 \mathrm{~g} / \mathrm{lit}$ \\
Glutamate & $0.0750 \mathrm{~g} / \mathrm{lit}$ & Simulation time & $120 \mathrm{hours}$ \\
Glutamine & $0.0100 \mathrm{~g} / \mathrm{lit}$ & S & \\
Isoleucine & $0.0520 \mathrm{~g} / \mathrm{lit}$ & & \\
\hline \hline
\end{tabular}

\section{Albumin synthesis model}

As we can see in Fig. 6 the albumin synthesis model fits the dataset. The improvement of the model for adapting the previous model to the case of co-culture was necessary, because in this case the albumin secretion starts faster than in the single culture. In the last days of culture albumin secretion reaches a plateau because of the lack of nutrients.

\section{CONCLUSION}

As evident from the equation set and from the results CREPE is a high expandable model able to simulate hepatocyte metabolism alone, endothelial cells metabolism alone, and their metabolism when they are in co-culture. It represents the first model that tries to consider the alteration of cellular metabolism in the co-cultures and it could help us to understand the complex communications that hepatocytes established with non-parenchymal cells. Hepatocytes crosstalk with non-parenchymal cells is not easy to understand because it is due to a great quantity of stimuli. In CREPE we considered two types of stimuli: Endothelin-1 mediated crosstalk that led to a slowing-down of hepatocytes glucose metabolism, and heterotypic contact that led to a correct hepatospecific genes expression. We modeled Endothelin-1 action as a genetic inhibition and our results are compatible with the experimental data. The choice of modeling heterotypic contact is due to the evidence that it is necessary for correct hepatocytes functionality. Furthermore our data show that albumin synthesis is faster in the case of co-culture (because of heterotypic contact). We validated CREPE considering its ability to model the complete co-culture data set (cell count, glucose trends and albumin trends) and the complete single-culture trends. However there are many other factors involved in cross-talking that we have not considered yet, like the role of growth factors or the role of topology in heterotypic contact. Future investigations about this topic, and so future improvement of CREPE, could regard the role of cross-talk in cell proliferation and the study of co-culture in presence of insulin.

\section{REFERENCES}

[1] H. Ogata, S. Goto, K. Sato, W. Fujibuchi, H. Bono, and M. Kanehisa, "KEGG: Kyoto Encyclopedia of Genes and Genomes," Nucleic Acids Research, vol. 27, no. 1, pp. 29-34, Jan. 1999.
[2] C. De Maria, D. Grassini, F. Vozzi, B. Vinci, A. Landi, A. Ahluwalia, and G. Vozzi, "HEMET: mathematical model of biochemical pathways for simulation and prediction of HEpatocyte METabolism.," Computer Methods and Programs in Biomedicine, vol. 92, no. 1, pp. 121-134, 2008.

[3] G. Orsi, C. De Maria, M. Guzzardi, F. Vozzi, and G. Vozzi, "HEMETß: improvement of hepatocyte metabolism mathematical model.," Computer methods in biomechanics and biomedical engineering, p. 1, Jan. 2011

[4] G. Orsi, C. De Maria, F. Vozzi, M. Guzzardi, A. Ahluwalia, and G. Vozzi, ENMET: Endothelial Cell Metabolism Mathematical Model. IEEE, 2009, pp. 654-659.

[5] M. A. Guzzardi, F. Vozzi, and A. D. Ahluwalia, "Study of the crosstalk between hepatocytes and endothelial cells using a novel multicompartmental bioreactor: a comparison between connected cultures and cocultures.," Tissue engineering. Part A, vol. 15, no. 11, pp. 3635-44, Nov. 2009.

[6] S. N. Bhatia, U. J. Balis, M. L. Yarmush, and M. Toner, "Effect of cellcell interactions in preservation of cellular phenotype: cocultivation of hepatocytes and nonparenchymal cells," FASEB J, vol. 13, no. 14, pp. 1883-1900, Nov. 1999.

[7] B. Vinci, E. Murphy, E. Iori, M. C. Marescotti, A. Avogaro, and A. Ahluwalia, "Flow-regulated glucose and lipid metabolism in adipose tissue, endothelial cell and hepatocyte cultures in a modular bioreactor.," Biotechnology Journal, vol. 5, no. 6, pp. 618-626, 2010.

[8] L. D. Monti, G. Valsecchi, S. Costa, E. P. Sandoli, C. V. Phan, A. E. Pontiroli, G. Pozza, and P. M. Piatti, "Effects of endothelin-1 and nitric oxide on glucokinase activity in isolated rat hepatocytes.," Metabolism: clinical and experimental, vol. 49, no. 1, pp. 73-80, Jan. 2000.

[9] D. L. Nelson and M. M. Cox, Lehninger Principles of Biochemistry, vol. 4th editio, no. v. 1. W. H. Freeman, 2005, p. 1100.

[10] W. S. Levine, The Control Handbook. CRC Press, 1996, p. 1566.

[11] L. Ljung, System Identification: Theory for the User, vol. 11, no. 3. Prentice Hall, 1987, pp. 71-73.

[12] J. E. Bailey and D. F. Ollis, Biochemical Engineering Fundamentals. McGraw-Hill Science/Engineering/Math, 1986, p. 928.

[13] J. Keener and J. Sneyd, Mathematical Physiology I: Cellular Physiology, vol. 8/1. Springer Verlag, 2009, p. 1067.

[14] H. de Jong, "Modeling and simulation of genetic regulatory systems: a literature review.," Journal of computational biology : a journal of computational molecular cell biology, vol. 9, no. 1, pp. 67-103, Jan. 2002.

[15] T. E. Barman, Enzyme Handbook, Springer-Verlag New York, Inc., 1969.

[16] N.S. Sharma, M.G. Ierapetritou, M.L. Yarmush, "Novel quantitative tools for engineering analysis of hepatocyte cultures in bioartificial liver systems", Biotechnol. Bioeng, vol .92, no. 3, pp 321-335, Nov. 2005

[17] K. R. Albe, M. H. Butler, and B. E. Wright, "Cellular concentrations of enzymes and their substrates.," Journal of Theoretical Biology, vol. 143, no. 2, pp. 163-195, 1990.

[18] R. N. Gutenkunst, J. J. Waterfall, F. P. Casey, K. S. Brown, C. R. Myers, and J. P. Sethna, "Universally Sloppy Parameter Sensitivities in Systems Biology Models," PLoS Computational Biology, vol. 3, no. 10, p. 8, 2007.

[19] M. Ashyraliyev, Y. Fomekong-Nanfack, J. A. Kaandorp, and J. G. Blom, "Systems biology: parameter estimation for biochemical models.," The FEBS journal, vol. 276, no. 4, pp. 886-902, 2009.

[20] G. Koh, H. F. C. Teong, M.-V. Clément, D. Hsu, and P. S. Thiagarajan, "A decompositional approach to parameter estimation in pathway modeling: a case study of the Akt and MAPK pathways and their crosstalk.," Bioinformatics, vol. 22, no. 14, pp. e271-e280, 2006.

[21] H. Akaike, "A Bayesian analysis of the minimum AIC procedure," Annals of the Institute of Statistical Mathematics, vol. 30, no. 1, pp. 914, 1978.

[22] T. A. Brieva and P. V. Moghe, "Functional engineering of hepatocytes via heterocellular presentation of a homoadhesive molecule, Ecadherin.," Biotechnology and bioengineering, vol. 76, no. 4, pp. 295 302, Dec. 2001.

[23] A. Cutrone, C. De Maria, B. Vinci, F. Vozzi, A. Ahluwalia, and G. Vozzi, "A new library of HEMET model: Insulin effects on hepatic metabolism.," Computer Methods and Programs in Biomedicine, vol. 94, no. 2, pp. 181-189, 2009. 